\title{
Role of endoscopic retrograde cholangiopancreatography after orthotopic liver transplantation
}

\author{
H J O'Connor, C R Vickers, J A C Buckels, P McMaster, J M Neuberger, R J West, E Elias
}

Liver Unit and

Department of

Radiology, Queen

Elizabeth Hospital, Birmingham

H J O'Connor

C R Vickers

J A C Buckels

P McMaster

J M Neuberger

R J West

E Elias

Correspondence to:

Dr H J O'Connor, General

Hospital, Tullamore,

Co Offaly, Eire.

Accepted for publication 25 May 1990

\begin{abstract}
Twelve of $178(7 \%)$ liver transplant patients underwent endoscopic retrograde cholangiopancreatography (ERCP) after transplantation. The indications for ERCP were persistent or late onset cholestasis, recurrent cholangitis, and suspected biliary leaks or strictures. The time between transplantation and ERCP ranged from 44 to 330 days (median 153 days). Biliary complications diagnosed by ERCP included biliary sludge in the form of casts, calculi, or debris $(n=7)$; bile leaks $(n=2)$; a biliary stricture $(n=1)$, and complete biliary obstruction $(n=1)$. One patient had a normal cholangiogram after transplantation. Biliary sludge was detected by ultrasound before ERCP in only one of six patients. Eight patients underwent endoscopic papillotomy, followed by clearance of biliary sludge in four and dilatation of a biliary stricture in one. Two patients bled after papillotomy but neither required surgical intervention. At a median follow up of 1.2 years (range 0.5-2.8 years), nine patients are well and three have died. ERCP provides both accurate diagnosis of biliary complications after liver transplantation and treatment that obviates the need for additional surgery in selected patients.
\end{abstract}

In the immunosuppressed patient after liver transplantation, biliary complications are

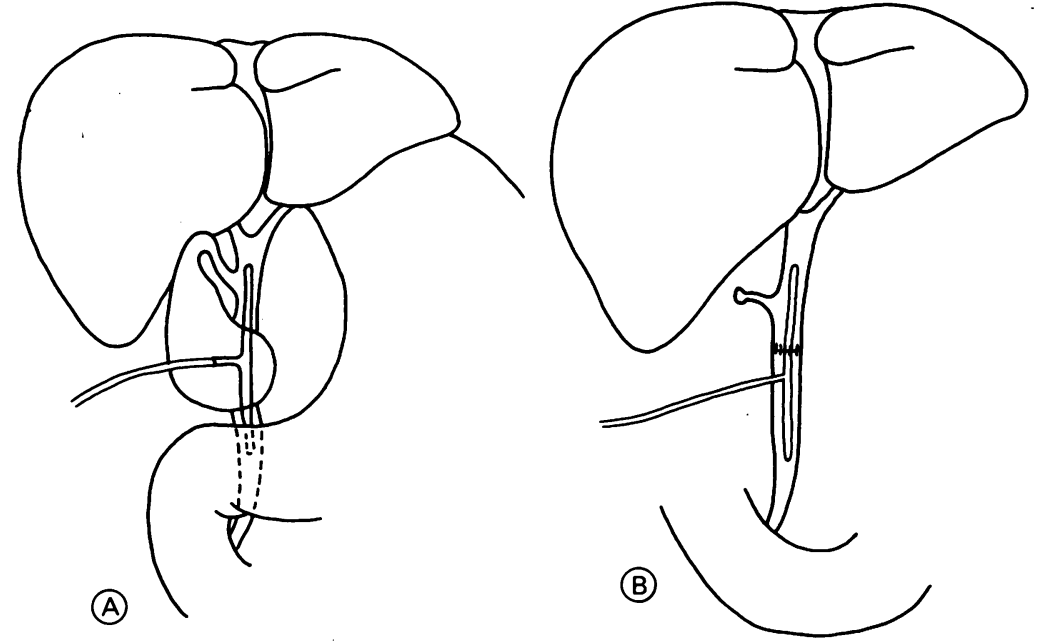

Figure 1: (A) Gall bladder conduit anastomosis. Biliary reconstruction using the donor gall bladder as a conduit. (B) Duct to duct anastomosis. Biliary reconstruction by choledochocholedochostomy. associated with a high mortality if they are not diagnosed and treated promptly. ${ }^{\prime}$ Furthermore, the clinical features and laboratory data associated with biliary complications may be similar to those of acute or chronic rejection, chronic sepsis, or cytomegalovirus infection. Hence, diagnostic imaging of the biliary tract is often required after liver transplantation. Although there are data on the roles of ultrasound, computed tomography, and percutaneous transhepatic cholangiography after transplantation, ${ }^{2}$ little attention has been paid to the value of endoscopic retrograde cholangiopancreatography (ERCP). In this report the diagnostic and therapeutic roles of ERCP in the postoperative management of liver transplant recipients are assessed.

Patients and methods

Between 19 January 1982 and 1 November 1988 178 patients received 206 orthotopic liver transplants at the Queen Elizabeth Hospital, Birmingham. The techniques of donor hepatectomy and graft implantation have been described elsewhere. ${ }^{3}$ Twenty one patients received a second and three patients a third transplant. There were 31 early postoperative deaths. Eighty one patients received immunosuppression with combination cyclosporin-prednisolone treatment and 66 received additional azathioprine.

Twelve of the $178(7 \%)$ patients underwent ERCP after transplantation and their details are shown in the Table. In seven of the 12 patients bile duct reconstruction was accomplished by the gall bladder conduit technique ${ }^{4}$ in which the donor gall bladder is used as a conduit with a proximal anastomosis between Hartmann's pouch and the donor common bile duct and a distal anastomosis between the fundus of the gall bladder and the recipient common bile duct (Fig 1A). In the remaining five patients, biliary reconstruction was accomplished by the duct to duct technique using an end to end choledochocholedochostomy (Fig 1B) with the long limb of a $\mathrm{T}$ tube brought out through a choledochotomy in the recipient's common bile duct.

INDICATIONS FOR ERCP

The main clinical indication for ERCP was cholestasis. In three patients, cholestasis had persisted since transplantation but in four it was 


\begin{tabular}{|c|c|c|c|c|c|c|c|c|}
\hline \multirow[b]{2}{*}{$\begin{array}{l}\text { Patient } \\
\text { No/sex/age }\end{array}$} & \multirow[b]{2}{*}{$\begin{array}{l}\text { Original } \\
\text { diagnosis }\end{array}$} & \multirow[b]{2}{*}{$\begin{array}{l}\text { Biliary } \\
\text { anastomosis }\end{array}$} & \multicolumn{6}{|l|}{$E R C P$} \\
\hline & & & Indication & $\begin{array}{l}\text { Time } \\
\text { interval } \\
\text { since } \\
\text { transplant } \\
\text { (days) }\end{array}$ & Findings & $\begin{array}{l}\text { Interventional } \\
\text { procedures }\end{array}$ & $\begin{array}{l}\text { Duration of } \\
\text { follow up } \\
\text { (years) }\end{array}$ & Outcome \\
\hline $1 / F / 42$ & PBC & $\mathrm{CD}$ & Suspected biliary leak & 89 & Biliary leak & None & $2 \cdot 8$ & Well \\
\hline $2 / \mathrm{F} / 42$ & PBC & $\mathrm{CD}$ & Recurrent cholangitis & 153 & Biliary debris & Papillotomy & $2 \cdot 5$ & $\begin{array}{l}\text { Second transplant for } \\
\text { chronic rejection. Well }\end{array}$ \\
\hline 3/M/59 & Hepatoma & $\mathrm{CD}$ & Persistent cholestasis & 162 & $\begin{array}{l}\text { Obstruction } \\
\text { above conduit }\end{array}$ & None & $1 \cdot 0$ & $\begin{array}{l}\text { Recurrent hepatoma. } \\
\text { Dead }\end{array}$ \\
\hline $4 / F / 51$ & $\begin{array}{l}\text { Subacute massive } \\
\text { hepatic necrosis }\end{array}$ & DD & Suspected biliary leak & 59 & $\begin{array}{l}\text { Anastomotic } \\
\text { leak }\end{array}$ & None & 0.6 & Cardiac arrest. Dead \\
\hline $5 / \mathrm{M} / 22$ & FHF & CD & Late cholestasis & 330 & Normal & None & 1.9 & $\begin{array}{l}\text { Second transplant for } \\
\text { chronic rejection. Well }\end{array}$ \\
\hline $6 / F / 36$ & PBC & CD & Late cholestasis & 172 & Biliary cast & Papillotomy & 0.6 & Well \\
\hline $7 / F / 28$ & FHF & $\mathrm{CD}$ & Persistent cholestasis & 90 & Biliary calculi & $\begin{array}{l}\text { Papillotomy, } \\
\text { Nasobiliary tube } \\
\text { inserted }\end{array}$ & $1 \cdot 2$ & $\begin{array}{l}\text { Recurrent biliary sludge. } \\
\text { Sepsis } 3 \text { months after } \\
\text { second transplant. Dead }\end{array}$ \\
\hline $8 / F / 40$ & EPP & $\mathrm{DD}$ & Late cholestasis & 262 & Biliary calculi & $\begin{array}{l}\text { Papillotomy, } \\
\text { balloon extraction }\end{array}$ & $0 \cdot 8$ & Well \\
\hline 9/F/48 & FHF & DD & $\begin{array}{l}\text { Biliary stricture, failed } \\
\text { percutaneous dilatation }\end{array}$ & 109 & $\begin{array}{l}\text { Anastomotic } \\
\text { stricture }\end{array}$ & $\begin{array}{l}\text { Papillotomy, } \\
\text { balloon dilatation }\end{array}$ & $0 \cdot 8$ & $\begin{array}{l}\text { Biliary reconstruction. } \\
\text { Well }\end{array}$ \\
\hline $10 / \mathrm{F} / 60$ & FHF & DD & Persistent cholestasis & 104 & Biliary cast & $\begin{array}{l}\text { Papillotomy, basket } \\
\text { extraction }\end{array}$ & $0 \cdot 5$ & Well \\
\hline $11 / M / 34$ & PSC & DD & Recurrent cholangitis & 44 & Biliary cast & $\begin{array}{l}\text { Papillotomy, } \\
\text { balloon extraction } \\
\text { nasobiliary tube } \\
\text { inserted }\end{array}$ & $0 \cdot 6$ & Well \\
\hline $12 / F / 55$ & PBC & $\mathrm{DD}$ & Late cholestasis & 185 & Biliary calculi & $\begin{array}{l}\text { Papillotomy, } \\
\text { balloon extraction }\end{array}$ & $1 \cdot 2$ & Well \\
\hline
\end{tabular}

$\mathrm{ERCP}=$ endoscopic retrograde cholangiopancreatography; $\mathrm{CD}=$ conduit duct $\mathrm{DD}=$ duct to duct $; \mathrm{EPP}=$ erythropoietic protoporphyria; $\mathrm{FHF}=$ fulminant hepatic failure; $\mathrm{PBC}=$ primary biliary cirrhosis; $\mathrm{PSC}=$ primary sclerosing cholangitis.

of later onset. Two patients had unexplained recurrent cholangitis and two had a suspected biliary leak. In one patient a biliary stricture had been found at $T$ tube cholangiography three months after transplantation, and attempts at percutaneous dilatation via the $\mathrm{T}$ tube track had failed.

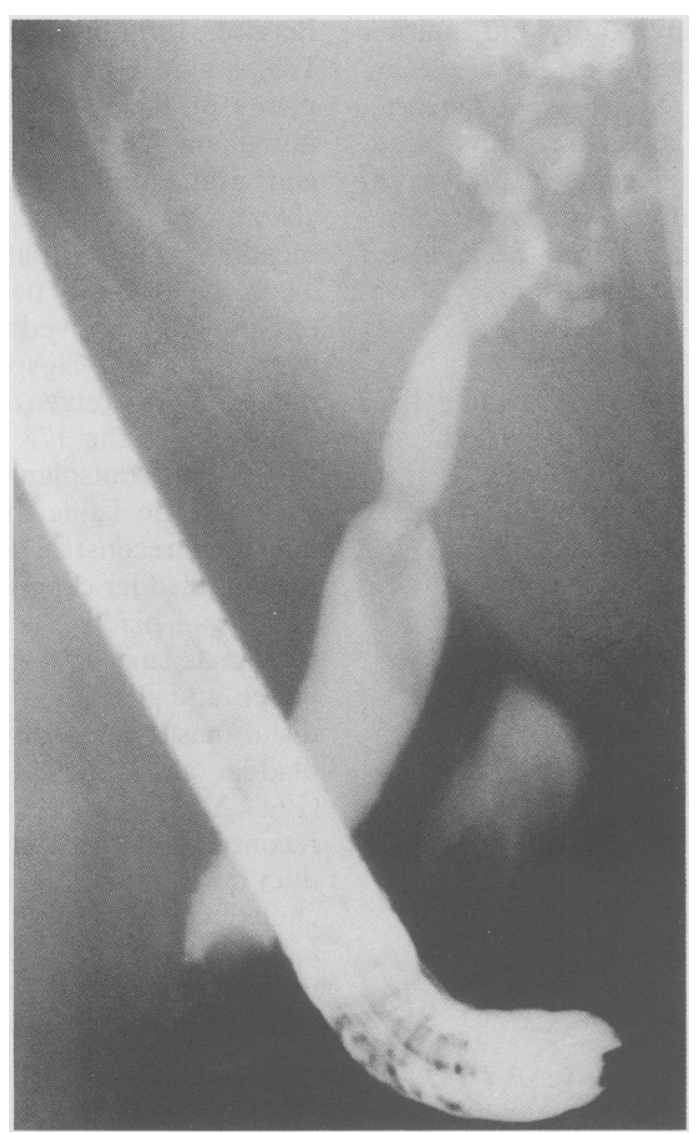

Figure 2: Biliary cast (patient 11) which was dislodged from the donor porta hepatis into the recipient common bile duct and then extracted after papillotomy using a Dormia basket.
The interval between transplantation and ERCP ranged from 44 to 330 days (median 153 days). The time to ERCP in the patients with late onset cholestasis ranged from 172 to 330 days (median 262 days), significantly longer than in the remaining eight patients $(p<0.05)$.

ERCP was performed once in five patients, twice in four patients, three times in two patients, and five times in one patient. All patients received antibiotic prophylaxis with intravenous cefuroxime one hour before ERCP and at four and 24 hours after the procedure. Patients were sedated with intravenous diazepam for the investigation and also received intravenous hyoscine butylbromide during the procedure to reduce duodenal peristalsis.

\section{Results}

ERCP FINDINGS

Cholangiography was successful in all 12 patients. Seven patients had evidence of sludge in the biliary tree in the form of casts, calculi, or debris. Biliary casts were detected in three patients - one with late onset cholestasis, one with persistent cholestasis, and one with recurrent cholangitis. The casts were at the level of the recipient common bile duct in two patients and the donor common bile duct in one (Fig 2). Discrete calculi were detected in three patients (two with late onset cholestasis and one with persistent cholestasis). These were at the level of the recipient common bile duct in one patient and the donor common bile duct in two (Fig 3). One patient with recurrent cholangitis had ERCP appearances consistent with a collection of biliary debris in the gall bladder conduit. Six of the seven patients with cholangiographic evidence of biliary sludge had ultrasound examination of the biliary tree performed before ERCP and in only one was sludge detected. 


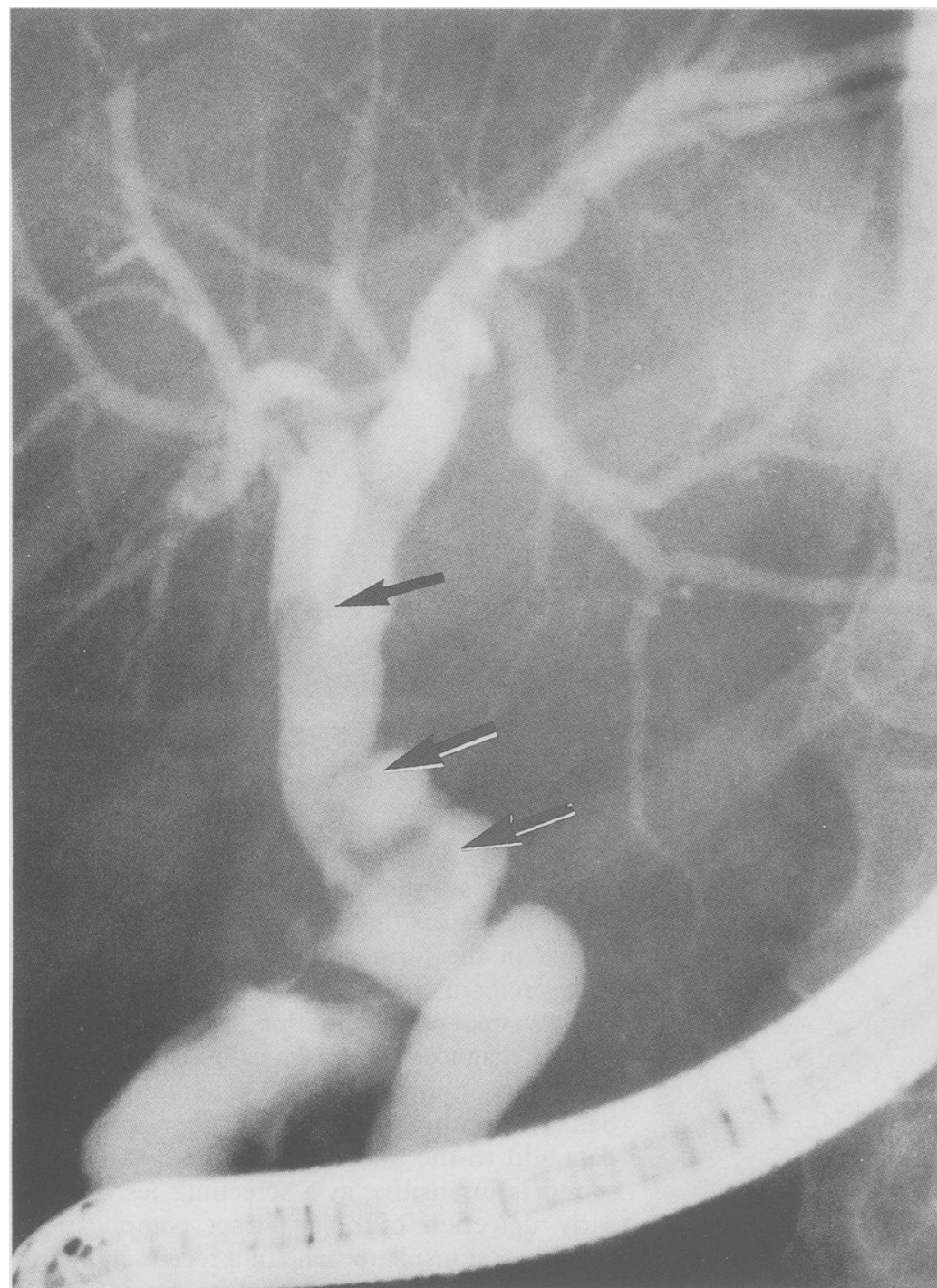

Figure 3: Biliary calculi (arrowed) (patient 8) which were extracted after papillotomy using a transendoscopic balloon catheter.

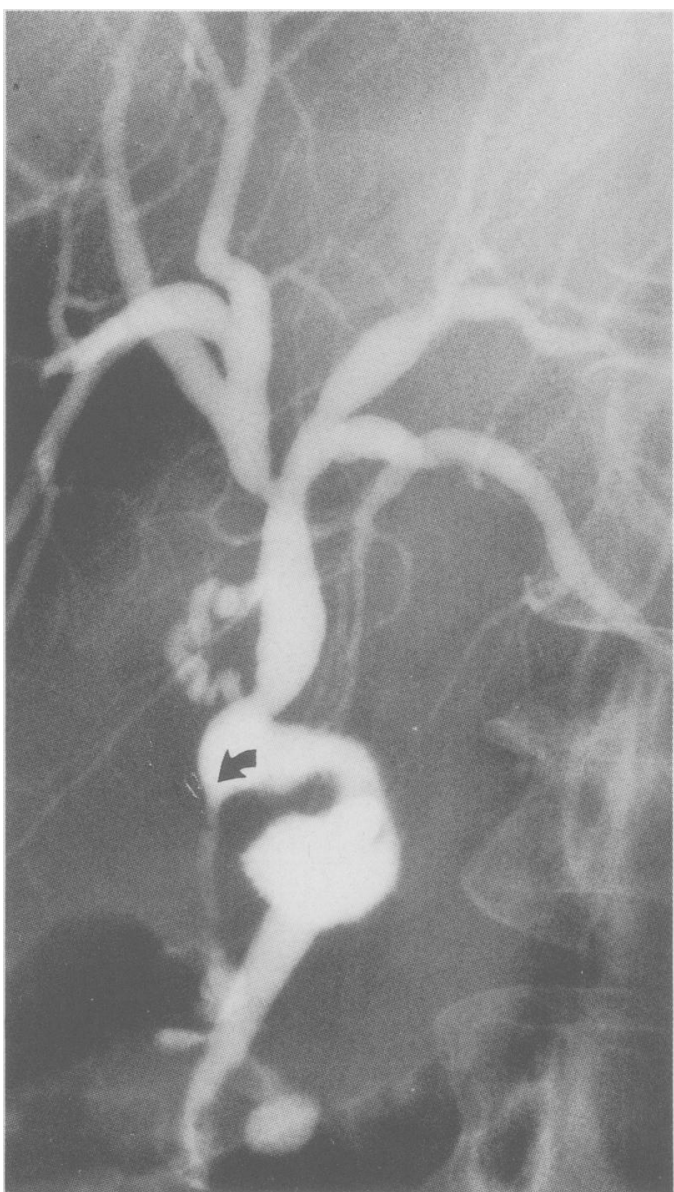

Figure 4: Anastomotic biliary leak (arrow) (patient 4).

with sludge had a nasobiliary tube inserted after papillotomy to flush the biliary tree with normal saline. The patient found to have a biliary stricture underwent attempted dilatation after papillotomy using graduated transendoscopic bougies to $11 \mathrm{FG}$ passed across the stricture over a teflon coated coaxial guide wire.

Two patients bled after papillotomy and None of the patients had ultrasonic evidence of biliary dilatation.

The presence of a biliary leak was confirmed at ERCP in two patients and the location of the leak was defined accurately (Fig 4). The presence of a biliary stricture was confirmed in one patient (Fig 5). One patient with persistent cholestasis had complete obstruction to the flow of contrast proximal to the gall bladder conduit (Fig 6) and a patient with late onset cholestasis had a normal cholangiogram after transplant (Fig 7).

\section{ENDOSCOPIC INTERVENTION}

Eight patients underwent endoscopic papillotomy, including all seven patients with biliary sludge. Papillotomy was followed by successful clearance of sludge from the biliary tract in four patients (two with calculi and two with casts) using a combination of transendoscopic balloon extraction catheters and Dormia baskets. All four patients had had a duct to duct biliary reconstruction. In contrast, attempted clearance of biliary sludge was unsuccessful in the three patients (one with casts, one with calculi, and one with debris) who had had a gall bladder conduit biliary reconstruction. Two patients 


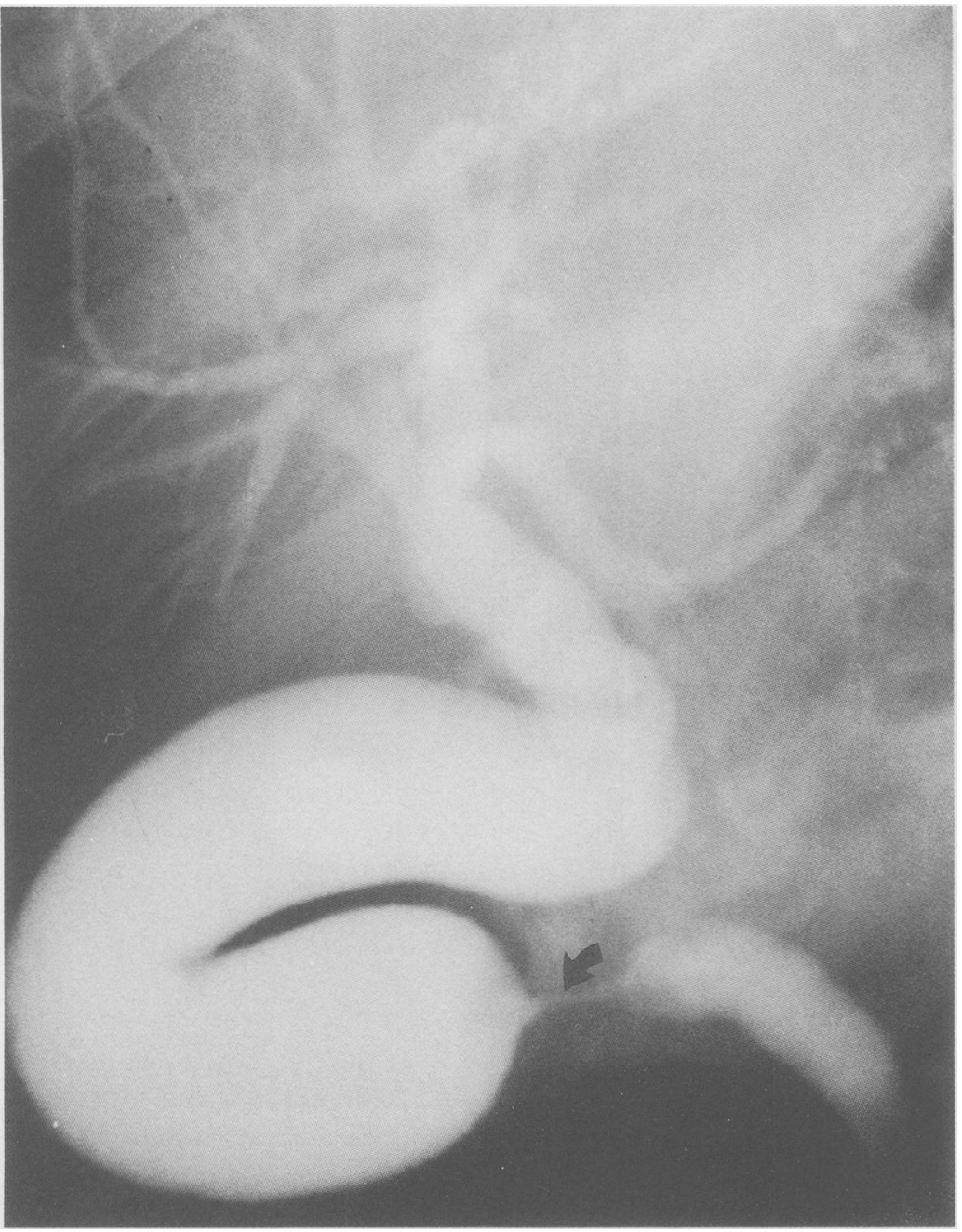

Figure 5: Anastomotic biliary stricture (arrow) (patient 9) with noticeable upstream dilatation of the donor common bile duct.

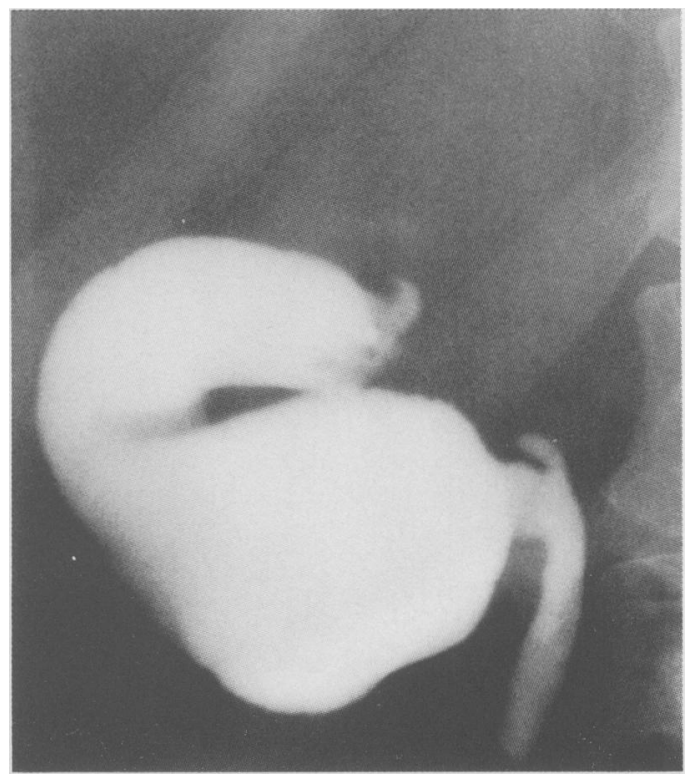

Figure 6: Cholangiogram (patient 3) showing complete obstruction to the flow of contrast proximal to the gall bladder conduit. Two casts were removed from the donor common bile duct at subsequent surgical exploration of the biliary tree.

tics of bile are thought to be important. ${ }^{5}$ Likewise, the factors that determine whether sludge occurs in the form of biliary casts, calculi, or debris remain unclear.

Only one patient in our series had biliary sludge diagnosed ultrasonically before ERCP and, furthermore, bile duct dilatation was not detected at ultrasound in this subgroup. These data add to the increasing evidence that ultrasound is insensitive as a screening test for the early detection of biliary tract complications after liver transplantation. In a recent comparative study in 50 liver transplant patients with biliary complications diagnosed by percutaneous transhepatic cholangiography, Zajko et $a l^{6}$ found that ultrasound had a sensitivity of only $46 \%$. Letourneau et $a l$ have shown that biliary obstruction after transplantation can be detected by computed tomography. However, the accuracy of this compared with direct cholangiography in the liver transplant patient has not been formally assessed.

Biliary leaks were diagnosed at ERCP in two patients, and their type and location were delineated accurately. Although bile collections suggestive of a leak from the biliary tree can be detected by ultrasound or computed tomography and fine needle aspiration, ${ }^{2}$ accurate diagnosis requires direct cholangiography, which in turn provides valuable information about the underlying aetiology, the likely clinical outcome and the treatment required. The most frequent site of bile leakage after transplantation is the $T$ tube choledochotomy, as shown in one of our patients. Most of these leaks are small and can be effectively treated by simple drainage. Anastomotic leaks, as in our second patient, are more serious and often require surgical repair.' Nonanastomotic leaks are a grave finding, usually occur in the hilar region, and result from bile duct necrosis secondary to hepatic artery thrombosis. ${ }^{8}$

To our knowledge, this is the first report of the use of endoscopic papillotomy in the manage- 


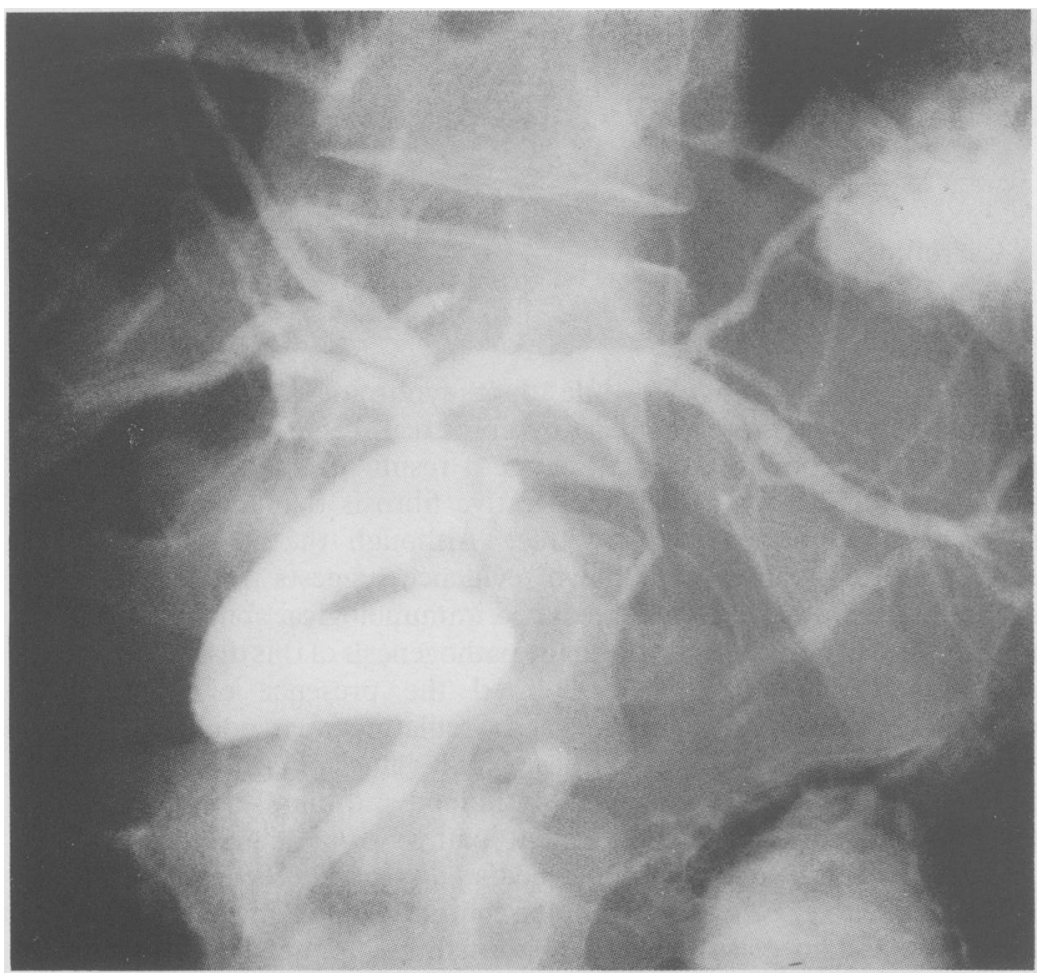

Figure 7: Cholangiogram (patient 5) showing no abnormality (gall bladder conduit anastomosis). the type of biliary reconstruction had a major impact on the endoscopist's ability to achieve bile duct clearance, with a high probability of success in patients who had a duct to duct reconstruction but not in those with a gall bladder conduit reconstruction. It is our experience that passage of transendoscopic catheters and baskets is facilitated by the relatively straight course of the biliary tree after duct to duct reconstruction but hindered by the tortuosity of the biliary tree after gall bladder conduit reconstruction. With the latter reconstruction it usually proved difficult to get out of the wide conduit into the narrow ostium of the donor common bile duct. Finally, no unexpected complications were encountered after ERCP in our patients.

1 Lerut J, Gordon RD, Iwatsuki S, et al. Biliary tract complications in human orthotopic liver transplantation. Transplantation 1987; 43: 47-51.

2 Zajko AB, Campbell WL, Bron KM, Schade RR, Koneru B, Van Thiel DH. Diagnostic and interventional radiology in liver transplantation. Gastroenterol Clin North Am 1988; 17: $105-43$.

3 Starzl TE, Iwatsuki SI, Esquival CO, et al. Refinements in the surgical technique of liver transplantation. Semin Liver Dis 1985; 5: 349-54.

4 Calne RY. A new technique for biliary drainage in orthotopic liver transplantation utilizing the gall bladder as a pedicle graft conduit between the donor and recipient common bile graft conduit between the donor a
ducts. Ann Surg 1976; 184: 605-9.

5 Starzl TE, Putnam CW, Hansbrough JF, Porter KA, Reid HAS. Biliary complications after liver transplantation: with special reference to the biliary cast syndrome and techniques of secondary duct repair. Surgery 1977; 81: 212-17.

6 Zajko AB, Zemel G, Skolnick ML, et al. Percutaneous transhepatic cholangiography rather than ultrasound as a screening test for postoperative biliary complications in liver transplant patients. Transplant Proc 1988; 20: 678-81.

ment of biliary complications after liver transplantation. The finding of biliary sludge was the main indication for papillotomy, which then allowed clearance of calculi and casts from the bile duct in four of seven patients, obviating the need for additional surgery. It is of interest that
7 Letourneau JG, Day DL, Maile CW, Crass JR, Ascher NL, Frick MP. Liver allograft transplantation: postoperative $\mathrm{CT}$ findings. AfR 1987; 148: 1099-103.

8 Zajko AB, Campbell WL, Logsdon GA, et al Cholangiographic findings in hepatic artery occlusion after liver transplantation. AfR 1987; 149: 485-9. 